\title{
Potential for Technological Modernisation and Innovation Based on ICT in Agri-Food Companies of Central Region of Portugal
}

\author{
Pedro D. Gaspar ${ }^{1,4}$, Vasco N. G. J. Soares ${ }^{2,3,4}$, and João M. L. P. Caldeira ${ }^{2,3,4}$ \\ ${ }^{1}$ University of Beira Interior, Covilhã, Portugal \\ ${ }^{2}$ Superior School of Technology, Polytechnic Institute of Castelo Branco, Castelo Branco, Portugal \\ ${ }^{3}$ Instituto de Telecomunicações, Portugal \\ ${ }^{4}$ InspiringSci, Castelo Branco, Portugal \\ Email: dinis@ubi.pt; \{vasco.g.soares, jcaldeira\}@ipcb.pt \\ Luís P. Andrade ${ }^{1}$ and Cláudia Domingues ${ }^{2}$ \\ ${ }^{1}$ Centro de Apoio Tecnológico Agro-Alimentar, Castelo Branco, Portugal \\ ${ }^{2}$ InovCluster, Castelo Branco, Portugal \\ Email: luispa@cataa.pt, claudiadomingues@inovcluster.pt
}

\begin{abstract}
This paper assesses the potential for technological modernisation and innovation based on Information and Communication Technologies (ICT) in agri-food companies located in the central region of Portugal. The survey was applied to 50 agri-food companies of Cereals, Cheese, Olive oil, Dry sausages, Honey, Wine, and Horticultural sectors. Survey results can be summarised as: The large majority of companies use computers and have Internet service. Most of companies don't have a webpage and neither use Internet for advertising campaigns, selling or buying products. Half of companies use social networks for business purposes. Most companies haven't promoted collaborators training in ICT in the last year. Companies claim that possessing a webpage and attending ICT training will be the technological solutions that will improve their productivity and/or marketing products and services. For each sector, recommendations and suggestions were provided in order to promote the use of ICT for business purposes.
\end{abstract}

Index Terms-ICT, agri-food, innovation, potential, analysis

\section{INTRODUCTION}

Information and Communication Technologies (ICT) and how they are used have been spreading at an astonishing speed. The latest figures (December 2014) for the European Union (EU) show that Internet is used by almost $77 \%$ of its population corresponding to a growth of almost 5 times between 2000 and 2014 [1]. More than half of EU citizens access the Internet every day (63\%), but a substantial minority (24\%) say that they never use the Internet or do not have access. Besides accessing the Internet from a computer (92\%), 61\% of Internet users access the Internet through a smartphone, and $30 \%$ use a touchscreen tablet. More than half of Internet users in the EU say they use the Internet to access their e-mail (86\%),

Manuscript received February 26, 2015; revised May 3, 2015. read news online $(63 \%)$, access online social networks $(60 \%)$, buy goods or services online $(57 \%)$ or do online banking (54\%), while $23 \%$ sell goods or services. Portugal is placed in tail of the EU countries, as only $48 \%$ of citizens use the Internet daily, 34\% never use Internet and $10 \%$ have no internet access. The overwhelming majority of Portuguese citizens (93\%) access the Internet via the computer (EU 92\%), followed by the smartphone for $38 \%$ (EU 61\%) and by the tablet for 22\% (EU 30\%). The leading online activity is using the email (PT 82\%, EU 86\%), followed by the use of online social networks (PT 76\%, EU 60\%), reading news online (PT 67\%, EU $63 \%$ ), perform online banking services (PT 26\%, EU $54 \%$ ) and purchasing goods or services (PT 20\%, EU $57 \%$ ). If it is considered the use of Internet for work or business purposes, more than one in three EU citizens $(38 \%)$ use the Internet while in Portugal this value round $25 \%$ [2]. As stated by Lehmann et al. [3], the efficiency, process control and consumer communications are all closely related to the use of ICT. Global networks, Internet, networked devices, sensors, online social networks and strategies and methodologies of communication are of prime relevance for the competitiveness and sustainable development of the food sector.

This paper is organized as follows. Section II describes the framework of the study. The state-of-the-art on the evaluation and application of ICT in the food sector and/or rural areas is described. The main objectives of the project that includes the assessment provided by this study are described.

Section III presents the materials and methods used to develop the analysis of the potential for technological modernisation and innovation based on ICT in agri-food companies of the central region of Portugal. The sequential steps that compose the methodology followed are described. The procedures for the questionnaire 
construction and for the survey implementation are presented.

Section IV includes the results from the compilation of the questionnaire answers and its analysis and discussion.

Section V gathers the suggestions and recommendations that identify improvement opportunities arising from the cross analysis in all sectors.

For last, Section VI describes the main conclusions of the study.

\section{FRAMEWORK}

One possible path to leverage the economic activity of food companies, in face of the economic recession installed, is to encourage the use of new technologies in small and medium enterprises (SME) of strategic and traditional sectors.

Lehmann et al. [3] provide an overview on the stateof-the-art in three use cases within the application domain of the food sector. The first case deals with management support for farming and the provision of appropriate IT support. The second one with logistics that might include aspects such as customer service, transportation, storage, plant site selection, inventory control, order processing, distribution, procurement, materials handling, return goods handling and demand forecasting. The last case focuses on the awareness, i.e. on the detailed information of food products and the proper communication to present and sell these food products. It focuses on the state-of-the-art on technology (networked devices and networks for communication), information content, organization and collection as well as data exchange and interoperability.

Some studies covered these use cases, from the implementation of new ICT [4]-[6], the proper determinants used to assess the ICT usage [7]-[8] and surveys on rural areas to determine the ICT usage. Botsiou and Dagdilelis [9] developed a study to evaluate the ICT profile of 29 farms in the northern region of Greece using a semi-structured interview process. They were not interested in evaluating whether a computer was available with an Internet connection for the needs of rural enterprise, but whether if it was used, for what purpose and in what way. The results of the research lead to the revelation of four kinds of ICT profiles in modern rural enterprises and also a way of covering the ICT skills gaps of the farmers, via social environment.

Sturiale and Scuderi [10] provide some indications about the involvement of social networks into the agrifood system. An online survey was applied to 500 followers of a page in the Facebook social network. The results predict an increase of social commerce and that enterprises need new forms of collaboration with consumers, especially within the online environment based on tools and interaction models as well as online platforms.

Moghaddam and Khatoon-Abadi [11] identified the factors influencing the adoption of ICT in a rural ICT centre of an Iranian province. The survey was applied to 218 individuals. Based on the results, the existence of an ICT centre reinforces the adoption of ICT regardless of the users' economic status. At the same time, factors such as individual, social, the households' informative \& communicative, as well as the innovation related factors were found influential on the use of ICT.

Senthilkumar et al. [12] performed a survey on a total of 270 respondents comprising of 180 users and 90 nonusers of Village Information Centres (VIC). A multiple linear regression analysis was applied to assess the factors associated with the VIC usage level in the study area. The study concluded that dairy farmers with higher land-holding size and dairy herd size, need good knowledge on dairy farming, so they are more likely to use VICs. Higher usage levels of VIC information contribute to knowledge gain, which in turn contributed to the effectiveness of VICs among the users.

So, the use of ICT by incorporating innovative features with added value, improving the skills of SMEs activity and promoting the modernization of regional business sector, will foster the economy and competitiveness of agri-food traditional sectors. Thus, there is the need for an urgent intervention outlined by the project MITTIC Technological Modernisation and Innovation based on ICT in strategic and traditional sectors. This European project aims to promote economic growth and employment by increasing competitiveness in economic, strategic and traditional sectors in the regions of Extremadura region of Spain and Centre and Alentejo regions of Portugal by proposing and/or implementing innovative models of organization and production processes based on the application of ICT. The project has the following strategic objectives:

- Increase the innovative capabilities in terms of ICT: through improved management of knowledge, based on shared structures that optimise the resources in Research, Development and Innovation (R\&D\&I) and which allow joint requirements and opportunities to be identified.

- Update traditional productive sectors in terms of technology based on natural and strategic resources, by applying new business models or improving existing ones based on knowledge and ICT.

- Exchange new applications, processes or valuing methods for products with productive sectors by means of ICT, to generate new opportunities for business or to promote business innovation in those that currently exist.

The project is developed by 12 partners, 7 from Spain and 5 from Portugal.

The first activity of the project is the analysis of the potential for technological modernisation and innovation based on ICT. This activity aims to develop an in-depth analysis of the use, introduction and adoption of ICT in manufacturing and sales processes in strategic and traditional sectors in Extremadura region of Spain and Centre and Alentejo regions of Portugal. A technological research of businesses in this sector on both sides of the border will be carried out. This paper presents the results of the survey on the use of ICT tools for manufacturing processes and for support, marketing and sales in order to 
assess the potential for technological modernisation and innovation based on ICT. The survey was applied to 50 agri-food companies belonging to Cereals, Cheese, Olive oil, Dry sausages, Honey, Wine and Horticultural sectors located in the central region of Portugal. This assessment will recommend and suggest solutions to increase the introduction and use rate for ICT tools in companies of each sector in order to improve their manufacturing and marketing processes. Furthermore, it will provide support, guidance and backing for the businesses being studied to introduce and implement support, marketing and sales tools. These recommendations and suggestions will be applied to a set of companies to evaluate the influence of ICT in the competitiveness and economic growth of agrifood traditional sectors.

\section{MATERIAL AND METHODS}

The methodology for analysis of the potential for technological modernisation and innovation based on ICT in agri-food companies of the central region of Portugal followed three sequential steps:

- Step 1 - Definition of the sample;

- Step 2 - Script structuring and construction of the questionnaire;

- Step 3 - Conducting interviews.

\section{A. Definition of the Sample}

The definition of the stratified sample required the following tasks:

- Identification of the different sub-sectors of the traditional agri-food sector with greater representation in central region of Portugal.

- Selection of the traditional agri-food companies for the sample (provided by the InovCluster Association of Agro-Industrial Cluster of the Centre region of Portugal) [13].

- Selection of alternative companies, to ensure in proper time, any failure or refusal response by the respondents of the pre-selected sample.

- Survey and validation of telephone and email contacts of the sample.

TABLE I. DETAILS OF THE COMPANIES SURVEYED.

\begin{tabular}{|c|c|c|c|c|c|}
\hline \multirow{2}{*}{ Sector } & \multirow{2}{*}{$\begin{array}{c}\text { No. of } \\
\text { companies } \\
\text { surveyed }\end{array}$} & \multicolumn{2}{|c|}{$\begin{array}{c}\text { No. } \\
\text { of workers }\end{array}$} & \multicolumn{2}{c|}{$\begin{array}{c}\text { Turnover } \\
{[\mathrm{m}]}\end{array}$} \\
\cline { 3 - 6 } & 15 & Min & Max & Min & Max \\
\hline Cereals & 9 & 1 & 5 & 2.5 & 100 \\
\hline Cheese & 9 & 1 & 5 & 50 & 800 \\
\hline Olive oil & 8 & 2 & 5 & 50 & 600 \\
\hline Dry sausages & 7 & 1 & 3 & 1 & 50 \\
\hline Honey & 5 & 1 & 5 & 1 & 100 \\
\hline Wine & 2 & 1 & 3 & 50 & \\
\hline Horticultural & & & & &
\end{tabular}

Table I shows the traditional agri-food sectors evaluated, the number of companies surveyed in each sector, as well as the range of variation of some data of these companies, such as the number of workers and turnover. The sector that contributed with most companies to the survey was the Cereals sector, followed by the Cheese sector. Only two companies from the
Horticultural sector participate in the survey, so the results for this specific sector are very limited.

As shown in Table I, most companies have between 1 and 5 workers, so they have a small dimension. In the case of a single worker, this person is at the same time the owner, the manager, and the worker who uses ICT. Note that the turnover range is limited to the information provided by the companies. Many of the companies that participated in the study did not provide this information.

\section{B. Script Structuring and Construction of the Questionnaire}

This step involved the definition of the screenplay for personal/telephone interview, supported by a number of issues directly related to readiness for the use of ICT tools. The questionnaire was composed by 50 questions about the following topics:

- Company information.

- Use of ICT and Internet access.

- Use of Internet and online social networking.

- E-commerce.

- ICT training.

- Other concepts.

After the end of the inquiry process, the database where replies were loaded was built automatically by the online application used. After loading the 50person/telephone questionnaire results, data was exported in CSV format (Coma Separate Values) compatible with spreadsheet software.

\section{Conducting Interviews}

This step focused on the face and telephone interview process. In order to proceed rapidly with the face interviews, the team responsible to perform the live interviews was composed by two duly qualified elements, which received specific training for this purpose. At first, a session for presenting the study objectives was performed, simulating the interview (identifying potential constraints in getting some answers) and the procedures required for loading the surveys in the online application (ensuring a permanent monitoring of fieldwork). Subsequently, results monitoring ensured the accuracy and quality of information obtained.

The live/telephone inquiry process took place between November 1 and December 15, 2014, resulting in 50 interviews validated. The main constraints to conduct the interviews were:

- Specificities of some sectors concerning the work period (night or all day in the field) making it difficult to conduct telephone calls or arrange scheduling.

- Reduced sensitivity to the issues raised, as the business environment in these sectors, with many family farms, demonstrates a strong detachment or perception of the issues involved (low qualifications and age of responsible/workers).

\section{RESULTS AND DISCUSSION}

The compilation of questionnaire answers is described in this section. Only the most relevant data is presented, 
compared between sectors and discussed. The data is subdivided by the topics that structured the script. The results (positive answers) are presented as percentage to allow the subsequent comparative analysis of the results. It is important to observe that in the Horticultural sector only two questionnaires were conducted, which reduces the possibility of analyzing the results.

\section{A. Use of ICT and Internet Access}

Fig. 1 shows the availability of a collaborator responsible for ICT area in the traditional agri-food companies. Most of the companies have no one in charge for this area, although the large majority (90\%) uses regularly ICT equipment as shown in Fig. 2.

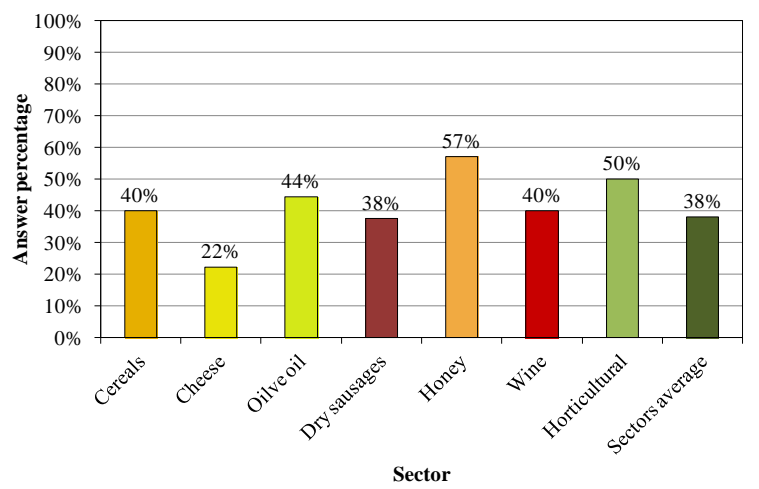

Figure 1. Availability of a collaborator responsible for ICT area.

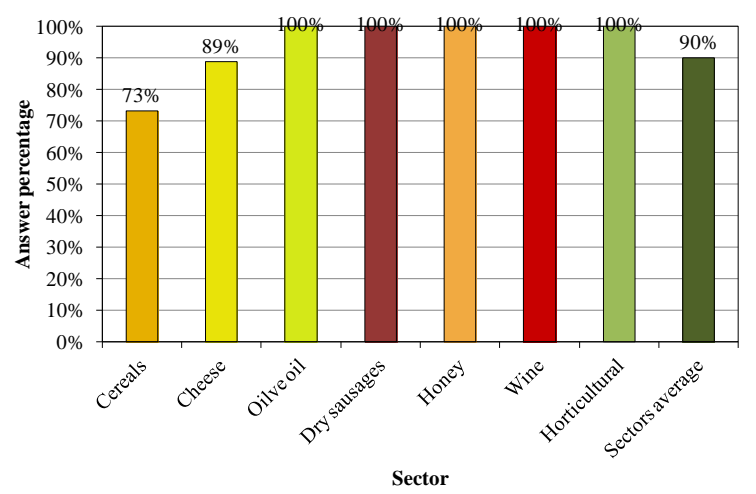

Figure 2. Regular use of ICT equipment.

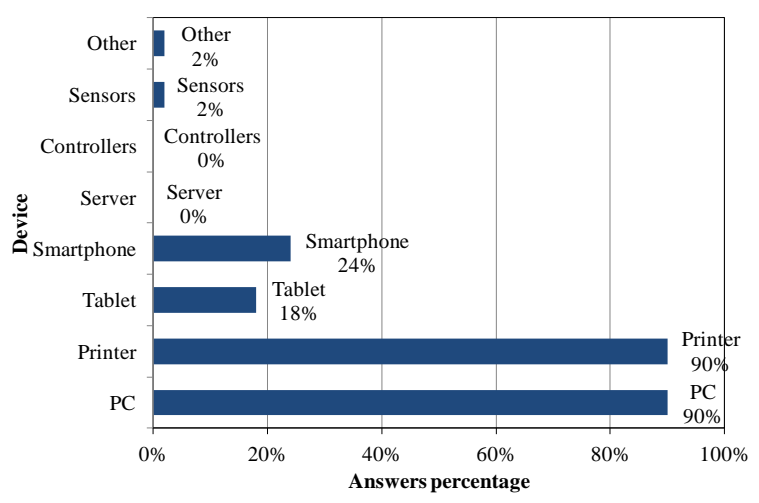

Figure 3. Type of ICT equipment used.

Similar to the data obtained in the EC survey [2], the computer is the usual equipment used to access Internet, although smartphone (24\%, EU 61\%) and touchscreen tablet (18\%, EU 30\%) are also used (see Fig. 3). The companies that answer negatively to this question pointed reasons such as: lack of training, high cost, no need for the business.

As shown in Fig. 4, most of the companies have Internet service. Cereals and Cheese sectors are those with less positive answers. Also, companies from these sectors, and in greater number, of Cereals sectors do not use mobile devices with Internet connection (see Fig. 5). Nevertheless, most of the agri-food companies (62\%) use this feature of their mobile devices to web navigation $(62 \%)$ and access e-mail account (64\%). The use of this feature for financial or industrial management applications is still reduced as shown in Fig. 6.

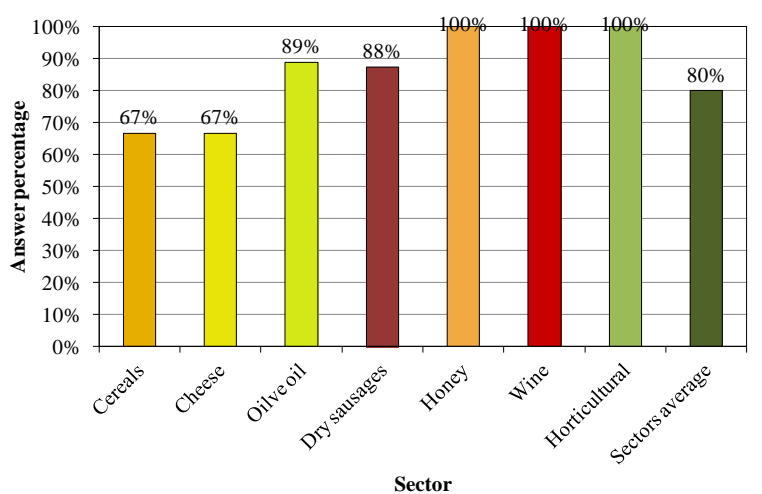

Figure 4. Availability of internet service.

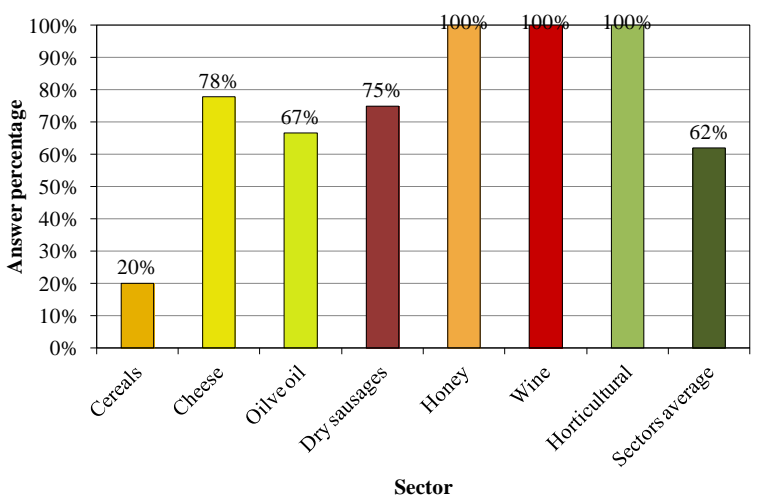

Figure 5. Use of mobile devices with internet connection.

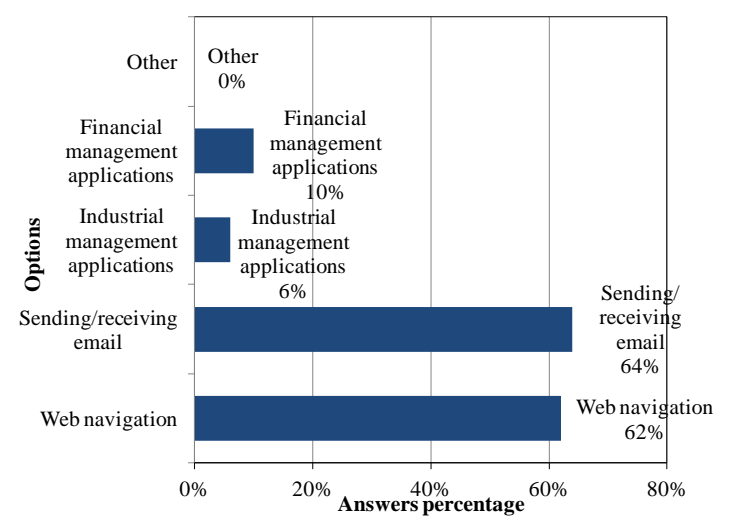

Figure 6. Use of mobile devices with Internet connection. 
Most companies do not have a Local Area Network (LAN) in their facilities $(60 \%)$. However, most of companies do have a corporate email address $(68 \%)$.

As shown in Fig. 7, most companies use regularly ICT tools for financial management $(72 \%)$, although almost exclusively they use invoicing tools (72\%). Thus, other ICT tools such as accounting tools and online banking are not usually used as shown in Fig. 8. Most of companies belonging to the Honey sector do not use these ICT tools (71\%).

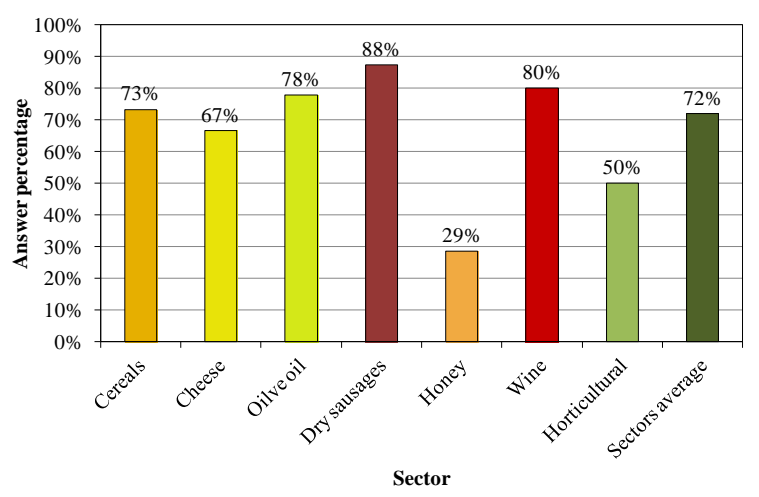

Figure 7. Regular use of ICT tools for financial management.

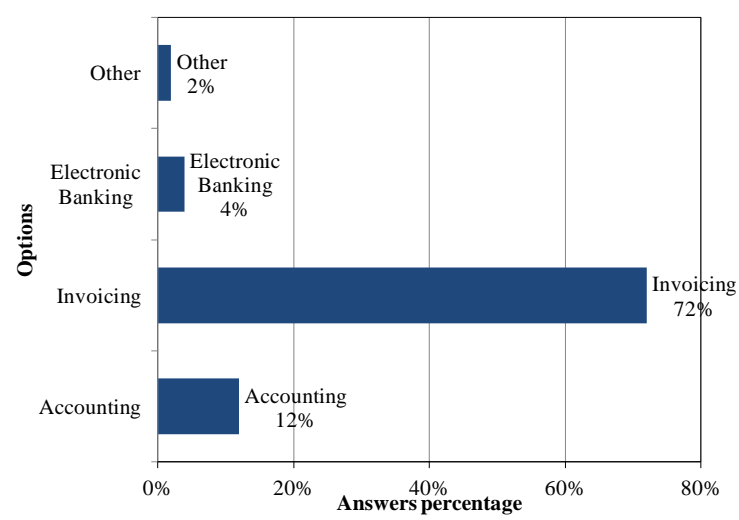

Figure 8. Type of ICT tools for financial management.

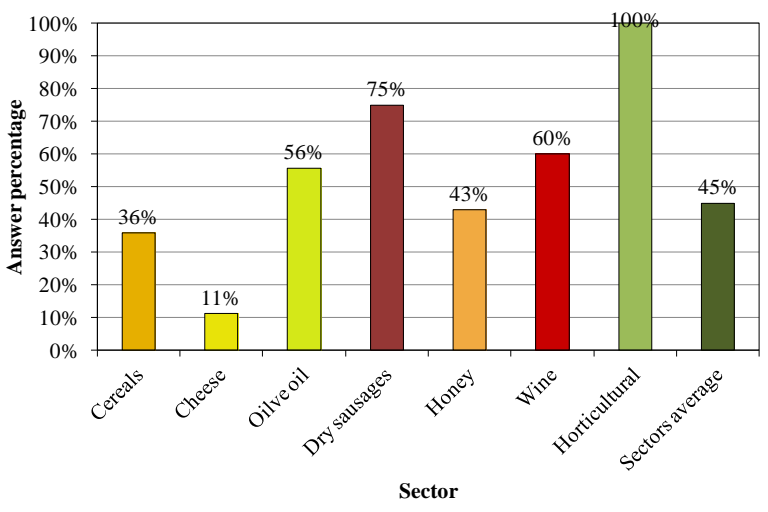

Figure 9. Regular use of a CRM system.

As shown in Fig. 9, less than half of companies regularly use Customer Relationship Management (CRM) systems to support tasks of buying analysis or planning sales $(45 \%)$. The majority of the companies belonging to the Cheese sector do not use this type of system (89\%).
Additionally, only one of the companies surveyed uses Enterprise Resource Planning (ERP) software.

$84 \%$ of companies expressed that they have processes oriented for quality management related with:

- Hazard Analysis and Critical Control Points (HACCP) required by Food Safety standards.

- Standard ISO 9001.

- Biological certification.

Additionally, $80 \%$ of companies stated that they use tools for products traceability. However, most of the tools used are not based in ICT.

The following question focused on the use and knowledge of computer security services to protect the ICT from cybercrime. $86 \%$ of companies claimed to use of a security service such as Antivirus and Firewall. Safety copies, authentication mechanisms and secure servers are not usual security services used by the companies. Nevertheless, these concerns about cybercrime are reflected in spreader use of online security tools as anti-virus software when compared with the results of EU, where $61 \%$ of the Internet users changed their online behaviour due to security concerns [2].

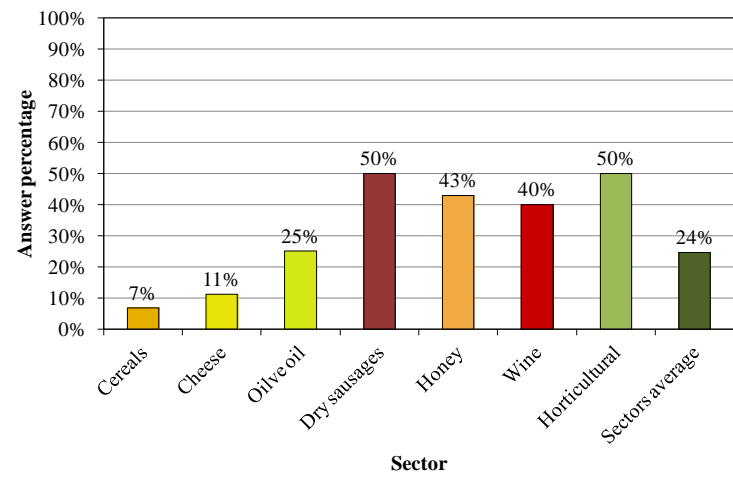

Figure 10. Existence of company webpage.

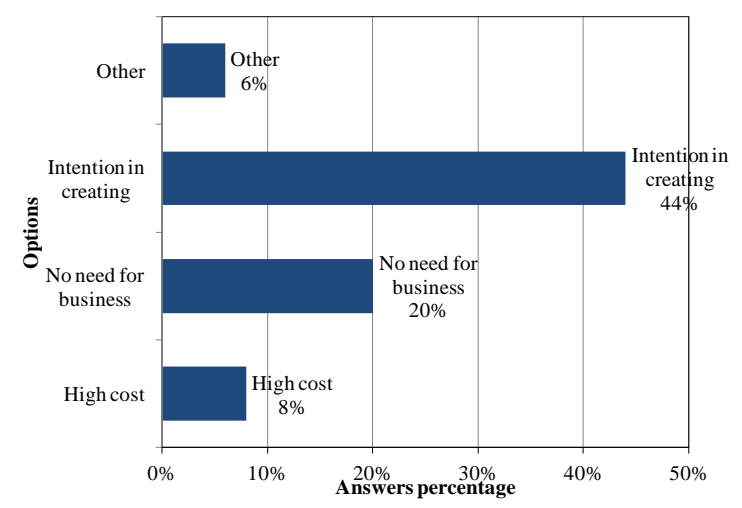

Figure 11. Reasons for lack of company webpage.

\section{B. Use of Internet and Online Social Networking}

Fig. 10 shows the percentage of companies that have a webpage. Most of the companies do not have it (24\%). Only half of companies of Dry sausages and Horticultural sectors have webpages. For the other sectors the availability of a webpage is even more reduced. However, most of the companies are interested in creating a webpage in the near future $(44 \%)$ as shown in Fig. 11. 
However, there are still companies that claim not to need a company webpage $(20 \%)$.

Most companies do not perform advertising campaigns through the Internet (60\%). However, companies belonging to Honey, Wine and Horticultural sectors are used to perform these type of campaigns (see Fig. 12).

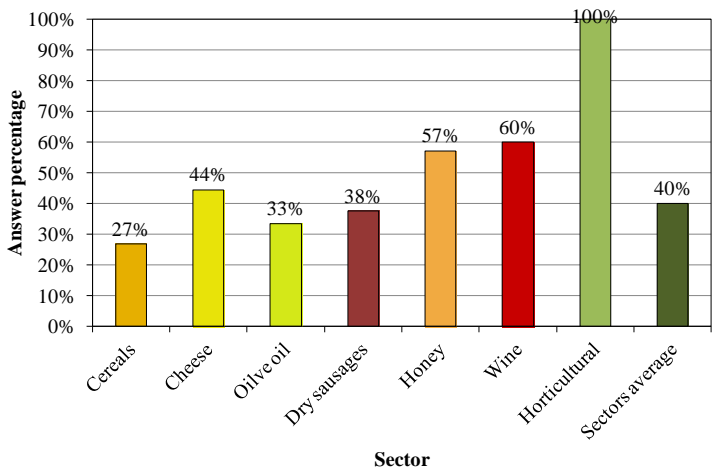

Figure 12. Promotion of advertising campaigns via Internet.

As shown in Fig. 13, half of the companies make use of social networks, mostly Facebook, for business purposes $(54 \%)$. There are a reduced number of companies of the Cereals sector performing this activity. The companies that provide a positive answer claim that online social networks are used as information channel for the consumer and to promote company marketing. Additionally, half of the companies make use of social networks to search for suppliers and customers (43\%).

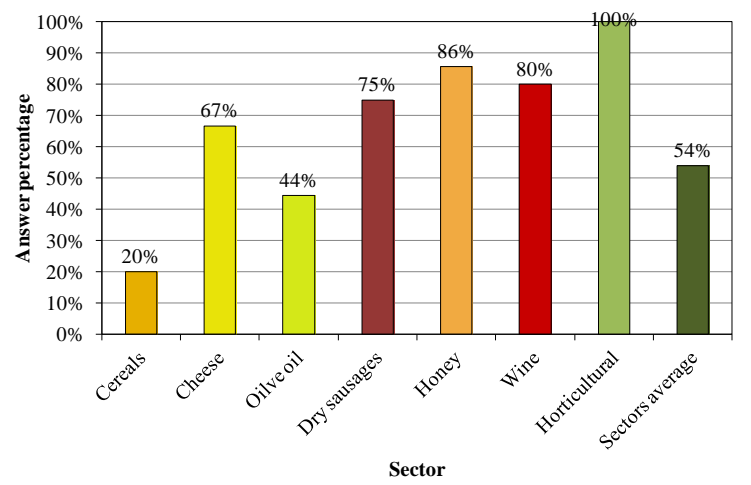

Figure 13. Use of social networks for business purposes.

\section{E-Commerce}

Most companies do not sale products online (74\%) as shown in Fig. 14. The companies belonging to the Cereals, Olive oil and Dry sausages do not make use of this potential use of ICT In the same sense, most companies do not purchase products for business over the Internet $(68 \%)$ and half of the companies do not perform markets research over the Internet (52\%).

\section{ICT Training}

Fig. 15 shows the investment of agri-food companies in ICT training during the last year. The training of company collaborators during the last year in ICT is very reduced in all agri-food sectors $(26 \%)$. Cereals, Honey and Wine sectors did not encourage its collaborators to improve their knowledge and skills in ICT.
The ICT training performed on the companies during the last year focused the following topics:

- Office tools (text processor and spreadsheet).

- Applications for company specific systems.

- Enterprise management tools.

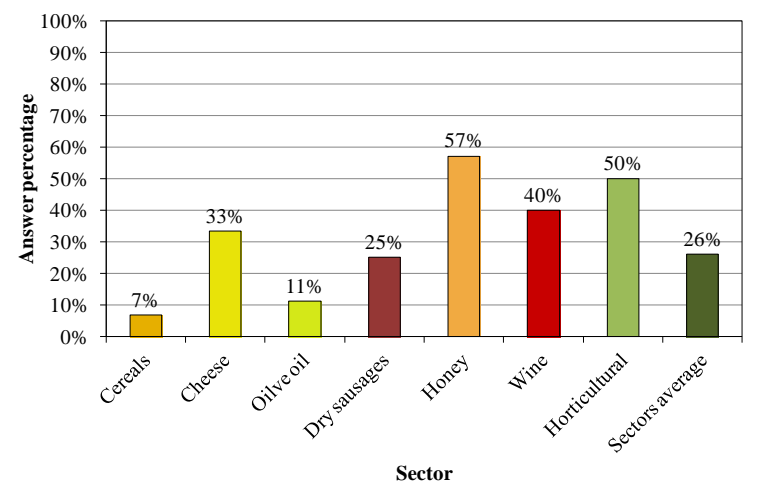

Figure 14. Companies selling products via Internet.

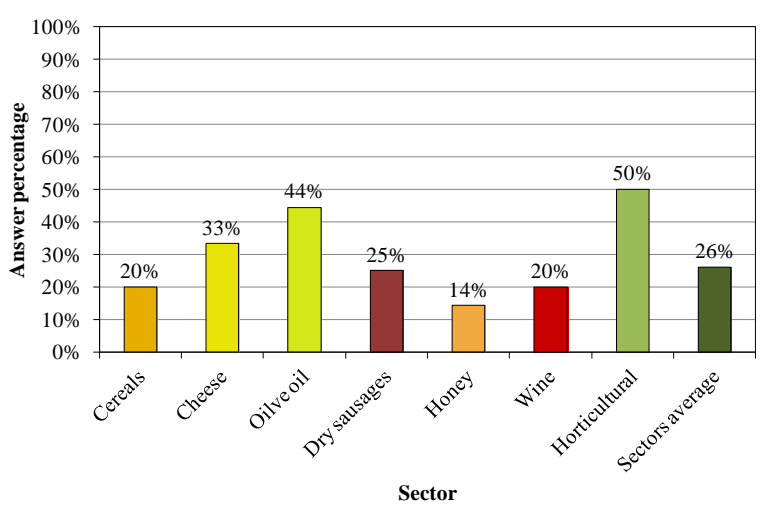

Figure 15. Training in ICT for company collaborators in the last year.

\section{E. Other Concepts}

The last question of the questionnaire asked owners, managers and workers of agri-food companies what are the equipment and/or technological solutions that may improve the company productivity and/or marketing of products and services. The overall answers are shown in Fig. 16. 55\% of companies think that possessing a company's webpage will improve company productivity and/or marketing of products and services. Also, $41 \%$ of companies reveal that these objectives may also be accomplished providing ICT training to their collaborators.

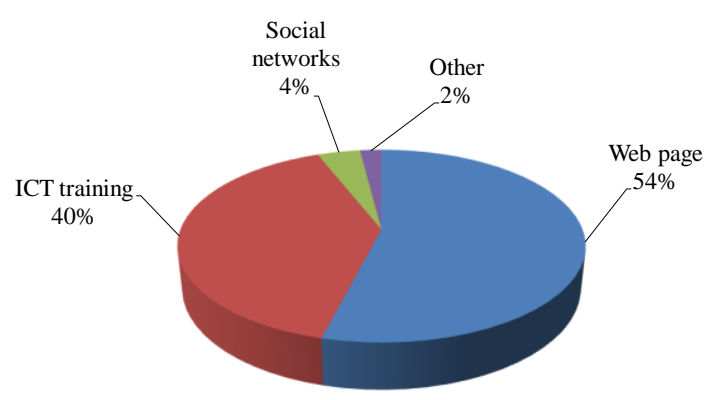

Figure 16. Equipment and technological solutions to improve productivity and/or marketing of products and services. 


\section{SUGGESTIONS AND RECOMMENDATIONS}

From a detailed analysis per sector, it turns out that the ICT usage is at approximately similar level. Thus, the following suggestions and recommendations that identify improvement opportunities arising from this analysis cross all sectors.

First of all, it is recommended to promote ICT training among company collaborators, specifically to who is in charge of management and finances in these micro and small companies. This training will promote the visibility of the company and foster e-commerce. The main objective is to make the owners/managers of these companies aware for the potential that the "virtual world" can offer to their businesses.

This objective can be accomplished pursuing the following recommendations:

- Creating the company webpage to promote visibility of the company and to perform advertising campaigns through the Internet and online product sales.

- Promoting ICT system upgrade in order to implement internal networks, which encourages setting corporate email and improves the communication between company employees. Thus, it is also recommended to assign the ICT responsibilities to a trained collaborator.

- Promoting the use of financial management tools, not only invoicing software. There are several suitable freeware tools for companies that do not want to affect more costs to this area.

- Promoting the use of Customer Relationship Management (CRM) systems.

- Promoting the use of Enterprise Resource Planning (ERP) systems.

- Promoting the use of ICT tools in the processoriented quality management.

- Promote the use of ICT tools in product traceability.

- Creating a company account on online social networks to promote the company's products.

This analysis provides a technological assessment of ICT that may help achieving more modernisation and technological innovation in the traditional and strategic sectors. However, not all companies are suited to apply this set of recommendations. The suggestions and recommendations in terms of ICT tools application will depend on the specific characteristics of the company. Thus, it is necessary an in-situ analysis to the manufacturing and marketing processes in order to determine the particular conditions that can be improved using ICT tools.

\section{CONCLUSIONS}

This paper presents the results of a survey for the assessment of the potential for technological modernisation and innovation based on ICT. The survey was applied to 50 agri-food companies belonging to Cereals, Cheese, Olive oil, Dry sausages, Honey, Wine, and Horticultural sectors located in the central region of Portugal. The main objective of this analysis is to propose actions and measures that promote economic growth and employment by increasing competitiveness in economy strategic and traditional sectors.

The analysis of results suggests that most company owners and/or managers use ICT tools, but at different levels. There are those that are familiarized in the use of ICT and use it in their enterprise, but also the precise opposite type where they claim total disinterest for ICT, either due to cost or no need for it application in their specific business. Although the study was perform in a single limited region of Portugal, what can be seen as limitation by reducing the results generalization, the results are especially useful for countries, like Portugal or Spain, with great opportunities to improve ICT diffusion rates.

From the results analysis, it is recommended to promote ICT training among company collaborators to improve the knowledge on ICT applications as well as their skills. These educational programs aim not only to improve these competences but also to change distrust and suspicion attitudes about ICT tools. The creation of webpages is also fundamental to promote the visibility of the company and to increase the e-commerce.

The recommendations and suggestions that result from the assessment will be applied to a limited set of companies to evaluate and measure the influence of ICT in the competitiveness and economic growth of agri-food traditional sectors.

\section{ACKNOWLEDGMENTS}

This research was supported by MITTIC. The MITTIC Project, Technological Modernization and Innovation based on ICT in strategic and traditional sectors, is financed jointly by the European Regional Development Fund (ERDF), through the Operational Programme of Cross-border Cooperation Spain - Portugal (POCTEP) 2007-2013.

\section{REFERENCES}

[1] Internet World Stats. (2013). Internet usage statistics for the European Union. [Online]. Available: http://www.InternetWorldStats.com

[2] European Commission, "Cyber Security Report - Special eurobarometer 423," European Commission (EC), DirectorateGeneral for Home Affairs, February 2015.

[3] R. J. Lehmann, R. Reiche, and G. Schiefer, "Future internet and the agri-food sector: State-of-the-art in literature and research," Comput. Electron. Agric., vol. 89, pp. 158-174, 2012.

[4] G. Schiefer, "New technologies and their impact on the agri-food sector: an economists view," Comput. Electron. Agric., vol. 43, pp. 163-172, 2004.

[5] A. Kaloxylos, J. Wolfert, T. Verwaart, C. M. Terol, et al., "The use of future internet technologies in the agriculture and food sectors: integrating the supply chain," Procedia Technology, vol. 8 , pp. 51-60, 2013.

[6] W. H. Mayer, "Integral ICT solutions supporting farmers businesses as well as environmental caretaking incl. Carbon optimization," Procedia Technology, vol. 8, pp. 550-553, 2013.

[7] P. Verdegem and L. De Marez, "Rethinking determinants of ICT acceptance: Towards an integrated and comprehensive overview," Technovation, vol. 31, pp. 411-423, 2011. 
[8] A. Bayo-Moriones and F. Lera-López, "A firm-level analysis of determinants of ICT adoption in Spain," Technovation, vol. 27, pp. 352-366, 2007.

[9] M. Botsiou and V. Dagdilelis, "Aspects of incorporation of ICT in the Greek agricultural enterprises: The case of a prefecture," Procedia Technology, vol. 8, pp. 387-396, 2013.

[10] L. Sturiale and A. Scuderi, "evaluation of social media actions for the agrifood system," Procedia Tech, vol. 8, pp. 200-208, 2013.

[11] B. K. Moghaddam and A. Khatoon-Abadi, "Factors affecting ICT adoption among rural users: A case study of ICT Center in Iran," Telecommunications Policy, vol. 37, pp. 1083-1094, 2013.

[12] S. Senthilkumar, M. Chander, A. S. S. Pandian, and N. K. S. Kumar, "Factors associated with utilization of ICT enabled Village Information Centres by the dairy farmers in India: The case of Tamil Nadu," Comput. Electron. Agric., vol. 98, pp. 81-84, 2013.

[13] InovCluster. (2013). MITTIC - Technological Modernisation and Innovation based on ICT in strategic and traditional sectors. [Online]. Available: http://www.inovcluster.pt

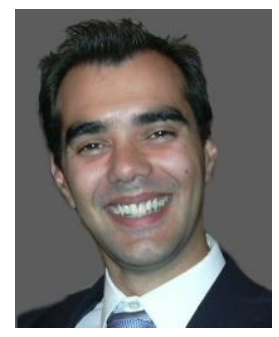

Pedro D. Gaspar is a Professor at the Department of Electromechanical Engineering of University of Beira Interior (Portugal). He is also Co-Founder of the start-up InspiringSci, Lda. He has a Ph.D. in Mechanical Engineering. His main research activities are related to the improvement of agri-food sector, either by the analysis of thermal performance and energy efficiency of commercial refrigeration equipment or ICT implementation. He coordinated several R\&D projects related with the improvement and the energy efficiency in the agri-food sector. His research has been published in peer-reviewed journals and book chapters.

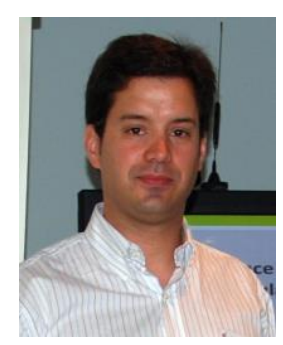

Vasco N. G. J. Soares is an Assistant Professor and Cisco Instructor at the Superior School of Technology of the Polytechnic Institute of Castelo Branco, Portugal, and a Researcher at the Instituto de Telecomunicações, Portugal. He is also CoFounder of the start-up InspiringSci, Lda. He received a Ph.D. degree in Computer Science and Engineering from the University of Beira Interior, Covilhã, Portugal. He has authored or co-authored more than 40 papers in refereed book chapters, journals, and conferences, and 2 patents. He is member of the editorial board of international journals. Also, he has participated in several national and European research projects. He is an IEEE Senior Member. His current research interests include vehicular networks, delay/disruption tolerant networks, Internet of everything, smart-cities, and technological solutions for the agro-industrial sector.

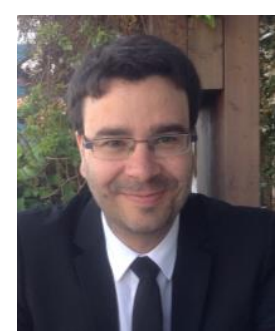

João M. L. P. Caldeira is an Assistant Lecturer at the Superior School of Technology of the Polytechnic Institute of Castelo Branco, Portugal, and a Researcher at the Instituto de Telecomunicações, Portugal. $\mathrm{He}$ is also Co-Founder of the start-up InspiringSci, Lda. He received the Ph.D. degree in Computer Science and Engineering from the University of Beira Interior, Covilhã Portugal and from the University of Haute Alsace, Colmar, France. He has authored or co-authored more than 20 papers in refereed book chapters, journals, and conferences. His current research interests include mobility support for wireless sensor networks, smart-cities, and technological solutions for agro-industrial sector.

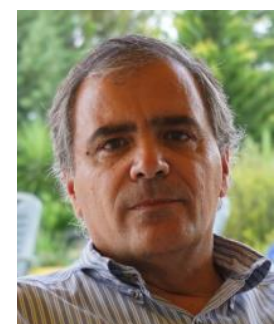

Luis P. Andrade. $\mathrm{PhD}$ in Veterinary Science from the University of Edinburgh - UK. Professor Coordinator in the School of Agriculture from the Polytechnic Institute of Castelo Branco (Portugal) in the areas of Animal Production Systems, Food Technology, Innovation and Development of New Food Products. Researcher at the Center for Natural Resource Studies, Environment and Society (CERNAS). He coordinated several R\&D projects in the areas of animal production systems, energy efficiency and life cycle analysis in the agro-industrial sector. Author and co-author of about 70 technical and scientific publications. Director of the Agri-Food Technological Center of Castelo Branco.

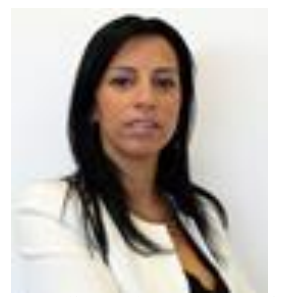

Cláudia Domingues has an $\mathrm{MSc}$ in Mechanical Engineering. Her main activities are related to the development of agri-food sector. She has experience in business cooperation strategies, internationalization of enterprises, innovation and development of new products for the agri-food sector. She is the Cluster Manager of InovCluster - Agro industrial Cluster (Portugal) since 2010. She coordinated several projects related with the agri-food sector. 